\title{
Early and long-term outlook of percutaneous coronary intervention for bifurcation lesions in young patients ${ }^{\text {th }}$
}

\author{
Sara Roversi a,*,1,2 , Giuseppe Biondi-Zoccai ${ }^{\text {b, 1,2 }}$, Enrico Romagnoli ${ }^{c, 1,2}{ }^{\text {, Imad Sheiban }}{ }^{\mathrm{d}, 1}$, \\ Stefano De Servi ${ }^{\text {e, }}$, Corrado Tamburino ${ }^{\mathrm{f}, 1}$, Antonio Colombo ${ }^{\mathrm{g}, 1}$, Francesco Burzotta ${ }^{\mathrm{h}, 1}$,
} Patrizia Presbitero i, ${ }^{\mathrm{i}}$, Leonardo Bolognese ${ }^{\mathrm{j}, 1}$, Leonardo Paloscia k, ${ }^{\text {, Paolo Rubino }}{ }^{\mathrm{l}, 1}$, Gennaro Sardella ${ }^{\mathrm{m}, 1}$, Carlo Briguori $^{\mathrm{n}, 1}$, Luigi Niccoli $^{\mathrm{o}, 1}$, Gianfranco Franco ${ }^{\mathrm{p}, 1}$, Domenico Di Girolamo ${ }^{\mathrm{q}, 1}$, Luigi Piatti $^{\mathrm{r}, 1}$, Cesare Greco $^{\mathrm{s}, 1}$, Sonia Petronio ${ }^{\mathrm{t}, 1}$, Bruno Loi ${ }^{\mathrm{u}, 1}$, Ernesto Lioy ${ }^{\mathrm{c}, 1}$, Alberto Benassi ${ }^{\mathrm{v}, 1}$, Aldo Patti ${ }^{\mathrm{w}, 1}$, Achille Gaspardone ${ }^{\mathrm{x}, 1}$, Davide Capodanno ${ }^{\mathrm{f}, 1}$, Maria Grazia Modena ${ }^{\mathrm{a}, 1}$, Giuseppe Sangiorgi ${ }^{\text {s, } 1}$

a Cardiology, University of Modena and Reggio Emilia, Modena, Italy

${ }^{\mathrm{b}}$ Medico-Surgical Sciences and Biotechnologies, Sapienza University of Rome, Latina, Italy

c Cardiology, Policlinico Casilino, Rome, Italy

${ }^{\mathrm{d}}$ Cardiology, University of Turin, Italy

e Dipartimento Cardiovascolare, Ospedale di Legnano, Milan, Italy

${ }^{\mathrm{f}}$ Cardiology, Ferrarotto Hospital, University of Catania, Catania, Italy

g Interventional Cardiology, San Raffaele Institute, and EMO-GVM Centro Cuore Columbus, Milan, Italy

h Cardiology, Catholic University, Rome, Italy

i Cardiology, Humanitas Mirasole Clinic, Rozzano, Milan, Italy

j Cardiovascular Department, San Donato Hospital, Arezzo, Italy

${ }^{\mathrm{k}}$ Interventional Cardiology, Santo Spirito Hospital, Pescara, Italy

Invasive Cardiology, Clinica Montevergine, Mercogliano, Italy

${ }^{\mathrm{m}}$ Cardiovascular Sciences, Policlinico Umberto I, Rome, Italy

${ }^{\mathrm{n}}$ Cardiology, Clinica Mediterranea, Naples, Italy

o Interventional Cardiology, Spedali Civili, Brescia, Italy

P Interventional Cardiology, Mater Salutis Hospital, Legnago, Italy

${ }^{q}$ Interventional Cardiology, San Sebastiano Hospital, Caserta, Italy

${ }^{r}$ Interventional Cardiology, Manzoni Hospital, Lecco, Italy

s Second Division of Cardiology, University of Rome, Rome, Italy

t Cardiology, Ospedale Cisanello, Pisa, Italy

u G. Brotzu Hospital, Cagliari, Italy

v Cardiology, Hesperia Hospital, Modena, Italy

${ }^{\mathrm{w}}$ Cardiovascular Department, Cervello Hospital, Palermo, Italy

${ }^{x}$ Cardiology, S. Eugenio Hospital, Rome, Italy

\section{A R T I C L E I N F O}

\section{Article history:}

Received 18 July 2012

Accepted 2 September 2012

Available online $\mathrm{xxxx}$

\section{Keywords:}

Age

Bifurcation

Coronary artery disease

Percutaneous transluminal coronary angioplasty

Stent

\begin{abstract}
A B S T R A C T
Background: Coronary artery disease is most common in older patients, but may occur in younger subjects. The outlook of young patients after percutaneous coronary intervention (PCI) of challenging lesion subsets such as coronary bifurcations, is not established. We thus aimed to appraise the early and long-term results of PCI for bifurcations in young patients.

Methods: A multicenter, retrospective study was conducted enrolling consecutive patients undergoing bifurcation PCI between 2002 and 2006 in 22 Italian centers. Patients were divided in 2 groups: age $\leq 45$ years, and age $>45$ years. The primary end-point was long-term rate of major adverse cardiac events (MACE).

Results: 4,314 patients were included: 195 (4.5\%) in the younger group, and 4119 (95.5\%) in the older group. 30-day outcomes did not show significant differences in MACE rates, with $1.0 \%$ in the $\leq 45$ years group and $2.1 \%$ in the $>45$ years group $(\mathrm{p}=0.439)$, with death in $0.5 \%$ and $1.2 \%(\mathrm{p}=0.388)$. At long-term follow-up (24.4 \pm 15.1 months), younger patients showed similar rates of MACE, (12.8\% vs. $16.6 \%, p=0.161)$, myocardial infarction ( $3.1 \%$ vs. $3.7 \%, \mathrm{p}=0.633)$, target lesion revascularization $(11.3 \%$ vs. $12.5 \%, \mathrm{p}=0.627)$, or stent
\end{abstract}

\footnotetext{
All authors take responsibility for all aspects of the reliability and freedom from bias of the data presented and their discussed interpretation.

* Corresponding author at: Cardiology, University of Modena and Reggio Emilia, Via del Pozzo 71, 41124 Modena, Italy. Tel.: + 390594225666 ; fax: + 39059302158. E-mail address: rov_sara@yahoo.it (S. Roversi).

${ }^{1}$ For the Italian Multicenter Registry on Bifurcation Study (I-BIGIS) Group.

2 Both authors equally contributed to this work.
} 
thrombosis ( $1.5 \%$ vs. $2.8 \%, \mathrm{p}=0.294)$, despite an increased risk of death in older patients ( $1.0 \% \mathrm{vs.} 5.0 \%, \mathrm{p}=$ $0.012)$. Even at extensive multivariable analysis, younger patients still faced a similar risk of MACE $(\mathrm{HR}=0.78$ [0.48-1.27], $\mathrm{p}=0.318$ ).

Conclusions: Despite their low age, young patients undergoing PCI for bifurcation face a significant risk of early and late non-fatal adverse events. Thus, they should not be denied careful medical management and follow-up.

(c) 2012 Elsevier Ireland Ltd. All rights reserved.

\section{Introduction}

Coronary bifurcation lesions still represent a challenge for interventional cardiologists. Even in the modern era, patients undergoing percutaneous coronary interventions (PCI) of bifurcation lesions face lower procedural success, greater complication rates and worse outcome compared with PCI of simple coronary lesions [1,2]. Advanced age has been traditionally identified as an important risk factor for adverse outcome in patients suffering from ischemic heart. Accordingly, older patients treated invasively usually have higher mortality rates, increased bleeding risk, and overall poorer outcomes [3-7].

Since age is a powerful determinant of prognosis, and advanced age is associated with worst results, could young age be related with better outcomes? A small number of trial have addressed this subjects, and even fewer data are available comparing results in different age groups in patients treated invasively for complex coronary lesions. Thus, we sought to determine the impact of young age on short and long-term outcome in patients undergoing $\mathrm{PCI}$ for bifurcation coronary lesions. We evaluated the rates of major adverse cardiovascular events (MACE) in patients enrolled in the Italian Multicenter Registry on Bifurcation (I-BIGIS) study, comparing events between subjects younger and older than 45 years.

\section{Methods}

The I-BIGIS was an Italian multicenter study enrolling consecutive patients undergoing percutaneous coronary bifurcation revascularization between January 2002 and December 2006. It included both elective and urgent admissions. Data collection and study design have been previously described $[8,9]$. Briefly, patients undergoing percutaneous revascularization at the site of a coronary bifurcation lesion of a major epicardial coronary artery and eligible for 1-year follow-up were included in the study. No specific exclusion criteria were adopted. All analyses were based on the actual procedural technique and implanted stent at the time of enrollment, regardless of previous myocardial revascularization. All patients provided written informed consent for the PCI procedure. The study protocol conforms to the ethical guidelines of the 1975 Declaration of Helsinki, and ethical committee approval was waived given the observational design.

\subsection{Study design and data collection}

This was a retrospective, observational clinical study sponsored by the Italian Society of Invasive Cardiology (SICI-GISE), where all the Italian catheterization laboratories constituting the SICI-GISE data set providers were invited to join the registry. Laboratories were included if they met the preset minimum requirements (routine performance of PCI, DES availability, and presence of a dedicated procedural database throughout the study period). Data for this study were drawn from a dedicated database. Given the observational and retrospective nature, all procedural aspects were left to center practice. Follow-up was based on hospital charts, direct visits, phone interviews and contacts with referring physicians.

\subsection{Clinical outcomes and definitions}

Primary end-point of our study was rate of MACE, assessed as the composite of cardiac death, $\mathrm{Q}$ wave and non-Q wave myocardial infarction (MI), target lesion revascularization (TLR), and stent thrombosis (ST) at 1 year or at the longest follow-up available. Secondary end-points were short-term (30-day) rate of MACE, and rates of singular adverse events both in short and long term follow-up.

As previously reported $[8,10]$, bifurcation lesions were defined as presence of $>50 \%$ diameter stenosis in a major epicardial coronary vessel, involving coronary bifurcation. Main vessel diameter had to be between 2.5 and $4.5 \mathrm{~mm}$, while side branch had to be between 2.25 and $4.5 \mathrm{~mm}$. Medina classification [11] was used to define true bifurcation lesions. Procedural success was defined as revascularization success without the occurrence of MACE during in-hospital stay. Cardiac death was defined as any death due to cardiac cause, or procedure-related deaths, and death of unknown cause. Myocardial infarction was defined according to the 2007 consensus statement from the Joint ESC/ ACCF/AHA/WHF task force [12]. Target lesion revascularization was defined as any revascularization procedure performed for angiographic restenosis within $5 \mathrm{~mm}$ proximal or distal to the treated lesion, associated with evidence of inducible myocardial ischemia. Stent thrombosis was assessed using the Academic Research Consortium definition [13] as definite, probable, or possible. To avoid any risk of tautology or redundancy, each patient could provide only one hard event per event type.

\subsection{Statistical analysis}

Baseline characteristics of the patients were summarized with means (standard deviation) for continuous variables and $\mathrm{n}(\%)$ for discrete variables. Student $\mathrm{t}$ and Yates corrected $\chi 2$ tests were used for bivariate analyses. Multivariable Cox proportional hazard analyses (reported as hazard ratio [HR] with 95\% confidence intervals) were performed to appraise the association between age group and long-term risk of MACE by adjusting for all covariates significantly $(p<0.05)$ associated with young age at bivariate analyses. Computations were performed with SPSS 20 (IBM, Armonk, NY, USA) and 2-tailed p values unadjusted for multiplicity are reported throughout.

\section{Results}

\subsection{Population characteristics}

This study comprised a total of 4,314 patients, enrolled between January 2002 and December 2006. The main clinical characteristics are reported in Table 1 . As expected, patients $\leq 45$ years old represented only a small share of the study population. Mean age in the young group was 41.4, compared with 65.5 in the older group $(\mathrm{p}<0.001)$.

Cardiovascular risk factors and comorbidities were significantly different between younger and older patients. Specifically, the latter presented higher incidence of diabetes, hypertension and chronic kidney disease (all $\mathrm{p}<0.05$ ). Conversely, young patients were more likely to be male, to smoke, and present a positive family history of cardiovascular disease (all $\mathrm{p}<0.05$ ). Interestingly, the prevalence of prior

Table 1

Baseline patient characteristics.

\begin{tabular}{|c|c|c|c|}
\hline Feature & $\begin{array}{l}\text { Age } \leq 45 \text { years } \\
(\mathrm{N}=195)\end{array}$ & $\begin{array}{l}\text { Age }>45 \text { years } \\
(\mathrm{N}=4119)\end{array}$ & $\mathrm{p}$ value \\
\hline Age (years) & $41.4 \pm 3.5$ & $65.5 \pm 9.7$ & $<0.001$ \\
\hline Male gender & $176(90.3 \%)$ & 3307 (80.3\%) & 0.001 \\
\hline $\begin{array}{l}\text { Family history of coronary artery } \\
\text { disease }\end{array}$ & $108(58.1 \%)$ & $1373(35.1 \%)$ & $<0.001$ \\
\hline Hypertension & $81(42.4 \%)$ & $2718(67.7 \%)$ & $<0.001$ \\
\hline Dyslipidemia & $120(62.8 \%)$ & $2317(57.8 \%)$ & 0.165 \\
\hline Smoking history & $141(73.8 \%)$ & $2049(51.1 \%)$ & $<0.001$ \\
\hline Diabetes mellitus & $15(7.9 \%)$ & $1081(26.9 \%)$ & $<0.001$ \\
\hline $\begin{array}{l}\text { Chronic kidney disease } \\
\quad \text { (serum creatinine }>1.7 \mathrm{mg} / \mathrm{dl})\end{array}$ & $5(2.7 \%)$ & $362(9.2 \%)$ & 0.002 \\
\hline Prior myocardial infarction & $50(29.2 \%)$ & $1208(32.5 \%)$ & 0.372 \\
\hline $\begin{array}{l}\text { Prior percutaneous coronary } \\
\text { intervention }\end{array}$ & $37(21.6 \%)$ & $991(26.7 \%)$ & 0.142 \\
\hline Prior coronary artery bypass grafting & $2(1.2 \%)$ & $360(9.7 \%)$ & $<0.001$ \\
\hline Multivessel coronary artery disease & $97(55.4 \%)$ & $2586(68.4 \%)$ & $<0.001$ \\
\hline $\begin{array}{l}\text { Concomitant unprotected left } \\
\text { main disease }\end{array}$ & $9(4.6 \%)$ & $318(7.7 \%)$ & 0.109 \\
\hline Left ventricular ejection fraction (\%) & $54.5 \pm 8.0$ & $52.5 \pm 9.4$ & 0.004 \\
\hline Admission diagnosis & & & $<0.001$ \\
\hline Stable angina & $88(45.1 \%)$ & $2141(52.0 \%)$ & \\
\hline Unstable angina & $37(19.0 \%)$ & $1001(24.3 \%)$ & \\
\hline $\begin{array}{l}\text { Non-ST-elevation myocardial } \\
\text { infarction }\end{array}$ & $22(11.3 \%)$ & $453(11.0 \%)$ & \\
\hline ST-elevation myocardial infarction & $48(24.6 \%)$ & $524(12.7 \%)$ & \\
\hline $\begin{array}{l}\text { Admission in a low volume } \\
\text { center }(<800 \mathrm{PCI} / \text { year })\end{array}$ & $59(30.3 \%)$ & $1026(24.9 \%)$ & 0.093 \\
\hline
\end{tabular}


myocardial infarction and prior percutaneous revascularization did not diverge between the two groups, while older patients had undergone a higher rate of surgical myocardial revascularization $(p<0.001)$.

Clinical presentation was again significantly different: aged patients were mostly admitted for angina, either stable or unstable, and presented more frequently with multivessel coronary artery disease. On the contrary, younger patients had greater frequency of myocardial infarction (STEMI or NSTEMI), and had higher left ventricular ejection fraction (all $\mathrm{p}<0.05$ ).

Finally, the prevalence of concomitant unprotected left main disease was similar between the groups, as the rate of hospitalization in a low volume PCI center.

\subsection{Procedural characteristics}

Main lesion and procedural characteristics are outlined in Table 2. The left anterior descending artery was the vessel more frequently involved in both groups, but comparison between bifurcation site in younger and older subject was significantly different (all $\mathrm{p}<0.05$ ). Particularly, patients $\leq 45$ years had higher incidence of left anterior descending/diagonal artery (72.8\% vs. $64.0 \%$ ) and right coronary/ posterior descending artery (6.7\% vs. $6.3 \%$ ) involvement. On the contrary, older patients presented more commonly with disease of the left main (8.8\% vs. 5.1\%), and left circumflex/obtuse marginal artery (21.0\% vs.15.4\%). Moreover, while the presence of multiple lesions or restenosis treatment was not significantly different, the rate of true bifurcation lesions was greater in the younger (73.0\% vs. $63.3 \%, \mathrm{p}=$ $0.009)$.

Conversely, few differences were high-lightened in procedural characteristics. As expected, patients $\leq 45$ years were more likely to receive drug-eluting stents $(\mathrm{p}=0.008)$, but stenting technique was alike between the two groups. Both younger and older patients received mostly stenting of the main branch, while T, V, crushing, culottes or other techniques were used in a minority of patients. Final kissing balloon was performed in about half of the procedures ( $56.9 \%$ of age $\leq 45$ years and $51.9 \%$ of age $>45$ years, $p=0.168$ ).

Additional IVUS imaging was effectuated in a minority of patients, and was not significantly different between groups. Vessel diameters

Table 2

Lesion and procedural characteristics.

\begin{tabular}{|c|c|c|c|}
\hline Feature & $\begin{array}{l}\text { Age } \\
\leq 45 \text { years } \\
(N=195)\end{array}$ & $\begin{array}{l}\text { Age } \\
>45 \text { years } \\
(\mathrm{N}=4119)\end{array}$ & P value \\
\hline Bifurcation site (\%) & & & 0.045 \\
\hline Left main & $10(5.1)$ & $363(8.8 \%)$ & \\
\hline Left anterior descending/diagonal artery & $142(72.8 \%)$ & $2635(64.0 \%)$ & \\
\hline Left circumflex/obtuse marginal artery & $30(15.4 \%)$ & $863(21.0 \%)$ & \\
\hline $\begin{array}{l}\text { Distal right coronary/posterior descending } \\
\text { artery/postero-lateral branch }\end{array}$ & $13(6.7 \%)$ & $258(6.3 \%)$ & \\
\hline True bifurcation lesion (\%) & $127(73.0 \%)$ & $2394(63.3 \%)$ & 0.009 \\
\hline Multiple lesions on the target vessel (\%) & $28(16.0 \%)$ & $673(18.2 \%)$ & 0.460 \\
\hline Restenosis treatment (\%) & $10(6.1 \%)$ & $185(5.1 \%)$ & 0.570 \\
\hline Stenting technique (\%) & & & 0.061 \\
\hline Main vessel stenting & $127(65.1 \%)$ & $2685(65.2 \%)$ & \\
\hline $\mathrm{T}$ & $16(8.2 \%)$ & $525(12.7 \%)$ & \\
\hline $\mathrm{V}$ & $33(16.9 \%)$ & $614(14.9 \%)$ & \\
\hline Crushing & $8(4.1 \%)$ & $115(2.8 \%)$ & \\
\hline Culottes & $10(5.1 \%)$ & $100(2.4 \%)$ & \\
\hline Other & $1(0.5 \%)$ & $74(2.0 \%)$ & \\
\hline Drug-eluting stent use (\%) & $166(85.1 \%)$ & $3173(77.0 \%)$ & 0.008 \\
\hline Main branch stent diameter (mm) & $3.1 \pm 0.4$ & $3.0 \pm 0.4$ & 0.424 \\
\hline Cumulative stent length on main branch (mm) & $21.4 \pm 7.8$ & $21.8 \pm 8.2$ & 0.480 \\
\hline Side branch stent diameter (mm) & $2.7 \pm 0.4$ & $2.7 \pm 0.4$ & 0.436 \\
\hline Cumulative stent length on side branch (mm) & $17.9 \pm 6.9$ & $18.8 \pm 8.6$ & 0.418 \\
\hline Final kissing balloon performed & $111(56.9 \%)$ & $2137(51.9 \%)$ & 0.168 \\
\hline Intravascular ultrasound & $9(4.6 \%)$ & $217(5.3 \%)$ & 0.689 \\
\hline Dual antiplatelet therapy duration (months) & $10.3 \pm 8.0$ & $9.8 \pm 8.7$ & 0.504 \\
\hline Angiographic control during follow-up & $69(37.1 \%)$ & $1359(33.7 \%)$ & 0.336 \\
\hline
\end{tabular}

and cumulative stent length was again comparable between younger and older patients.

Finally, both groups had similar duration of dual antiplatelet therapy, and received similar rates of angiographic control during follow up.

\subsection{Clinical outcomes}

Thirty-day clinical outcomes were comparable in the two groups (Table 3$) .2$ (1.0\%) patients $\leq 45$ years suffered a MACE vs. $88(2.1 \%)$ of those $>45$ years $(p=0.439)$. Death occurred in 1 younger $(0.5 \%)$ and in $49(1.2 \%)$ older subjects $(\mathrm{p}=0.388)$. Incidence of myocardial infarction, target lesion revascularization and definite stent thrombosis at thirty-day did not significantly differ, although it was slightly more frequent in older patients.

Moreover, the primary end-point was not significant, as the rate of MACE at 24 months did not show any difference between the two groups [25 (12.8\%) in age $\leq 45$ years vs. 685 (16.6\%) in age $>45$ years, $\mathrm{p}=0.161]$.

Conversely, an increased risk of death was recorded for older patients. The rates of cardiac death (3.3\%) and all cause death (5.0\%) were higher in aged patients than in younger subjects $(0.5 \%$ and $1.0 \%$ respectively), and the difference proved significant (both $\mathrm{p}<0.05$ ).

On the other hand, comparable rates were obtained for other clinical outcomes, as incidence of myocardial infarction [6 (3.1\%) in age $\leq 45$ years vs. 154 (3.7\%) in age $>45$ years, $\mathrm{p}=0.633$ ], target lesion revascularization [22 (12.3\%) vs. $513(12.5 \%), \mathrm{p}=0.627$ ] or stent thrombosis [3 (1.5\%) vs. 115 (2.8\%), p =0.294]. Even at extensive multivariable analysis, younger patients still faced a similar risk of MACE at long-term follow-up, in comparison to older patients (hazard ratio $=$ 0.78 [0.48-1.27], $\mathrm{p}=0.318$ ).

\section{Discussion}

In the present study, we compared short and long-term clinical outcomes in younger and older patients treated for coronary bifurcation lesions in the largest dedicated registry data to date, including a total of 4,314 patients. The main findings of this study were: 1) coronary bifurcation lesions represent an interventional challenge, with rates of long-term MACE of $12-16 \% ; 2$ ) early (thirty-day) outcomes did not show significant differences in MACE rates; 3 ) even though older patients faced an increased risk of death, even long-term rates of MACE were similar between older and younger patients.

Coronary bifurcation lesions account for up to $15 \%-20 \%$ of all current percutaneous revascularizations, and represent challenging subsets,

Table 3

Thirty-day and long-term clinical outcomes.

\begin{tabular}{llll}
\hline Event & $\begin{array}{l}\text { Age } \\
\leq 45 \text { years } \\
(\mathrm{N}=195)\end{array}$ & $\begin{array}{l}\text { Age } \\
>45 \text { years } \\
(\mathrm{N}=4119)\end{array}$ & \\
& & & \\
\hline Thirty-day outcomes & $2(1.0 \%)$ & $88(2.1 \%)$ & 0.439 \\
$\quad$ Major adverse cardiac events & $1(0.5 \%)$ & $49(1.2 \%)$ & 0.388 \\
Death & 0 & $38(0.9 \%)$ & 0.416 \\
Myocardial infarction & $1(0.5 \%)$ & $27(0.7 \%)$ & 0.637 \\
Target lesion revascularization & 0 & $23(0.6 \%)$ & 0.623 \\
Definite stent thrombosis & & & \\
Long-term outcomes $(24.4 \pm 15.1$ months $)$ & $25(12.8 \%)$ & $685(16.6 \%)$ & 0.161 \\
Major adverse cardiac events & $2(1.0 \%)$ & $205(5.0 \%)$ & 0.012 \\
Death & $1(0.5 \%)$ & $134(3.3 \%)$ & 0.032 \\
Cardiac death & $6(3.1 \%)$ & $154(3.7 \%)$ & 0.633 \\
Myocardial infarction & $22(11.3 \%)$ & $513(12.5 \%)$ & 0.627 \\
Any target lesion revascularization & & & \\
Stent thrombosis & $3(1.5 \%)$ & $56(1.4 \%)$ & 0.834 \\
$\quad$ Definite & 0 & $17(0.4 \%)$ & 1.0 \\
$\quad$ Probable & 0 & $42(1.0 \%)$ & 0.261 \\
$\quad$ Possible & $3(1.5 \%)$ & $115(2.8 \%)$ & 0.294 \\
$\quad$ Definite, probable or possible & & & \\
\hline
\end{tabular}


with lower rates of angiographic and procedural success [14-16]. Given the relative frequency and the overall complexity of coronary bifurcation lesions, many works have addressed this topic, focusing mainly on stenting techniques, and BMS vs. DES use [17-19]. Moreover, many authors have investigated age in large cohorts of patients undergoing $\mathrm{PCI}$, reporting it to be an independent predictor of both in-hospital and long-term mortality $[7,20,21]$. However, few data are available on outcome in patients receiving treatment for coronary bifurcation lesions stratified by age. Advancing age seems to have detrimental effects on both endothelial function and vascular remodeling, including intimal and medial thickening, and increased wall stiffness [22,23]. Thus, younger age has implicitly been considered a positive prognostic factor. Given this, we aimed to investigate the actual impact of younger age on MACE, both in the short- and long-term, of patients undergoing treatment for complex coronary lesions.

First of all, overall rates of procedural success in our registry were high, with thirty-day MACE reported in $2 \%$ of patients, and $<1 \%$ rate of definite stent thrombosis. Long-term (24.4 \pm 15.1 months) MACE occurred in about $16 \%$ of the total study population, with rates of death and stent thrombosis respectively of $4.7 \%$ and $2.7 \%$. Rates of adverse cardiac events are quite variable across literature, reflecting continuous improvement over time, in stenting techniques and devices $[1,15,18,24-27]$. Overall, we experienced a relatively low rate of MACE, and our results are in line with previous studies.

Many studies have focused on bifurcation coronary lesions and have reported worst outcome with advancing age [8,28-30]. To assess whether younger age ( $<45$ years) had any impact on outcome, we analyzed data from an Italian multicenter registry of unselected patients undergoing PCI of coronary bifurcations, representing the largest database to date. However, the results of our study are quite unexpected. Young patients face a similar risk of short-term MACE as their older counterpart, with no significant difference in terms of death, myocardial infarction, TLR or stent thrombosis. Moreover, similar results were obtained for long-term outcome, with the exception of death and cardiovascular death, both significantly higher in patients older than 45 years. Baseline characteristics in our population were significantly different between older and younger patients. Unsurprisingly, higher prevalence of hypertension, diabetes, chronic kidney disease, and prior CABG was reported in the older group. Moreover, these patients seemed to suffer from a more severe ischemic heart disease, as they presented higher rates of multivessel disease, lower left ventricular ejection fraction, and left main was more frequently involved.

As reported previously, young patients with ischemic heart disease are more likely to be smokers and to have a positive family history [31-33]. In our registry, while older patients were more likely to present with angina, younger subjects were usually admitted for myocardial infarction. Despite different baseline characteristic, all patients underwent similar treatment; thus, stenting techniques and procedural characteristics differed only in DES or BMS use, since younger patients were more likely to be treated with drug eluting stents. Other characteristics, like stenting technique, stent dimensions, final kissing balloon, use of IVUS, or angiographic control were similar between patients older or younger than 45 years.

As stated above, only death and cardiovascular death in the longterm was significantly different between the two groups. Overall MACE, both at short and long-term follow-up did not diverge. No clear explanation is available for these findings. Age, diabetes, and chronic kidney disease have all been linked to increased risk of death in patients undergoing PCI, thus just the baseline differences could justify increased mortality $[6,34,35]$.

However, these same characteristics have been linked with increased MACE as well, something that clashes with our own results. No obvious explanation can be advocated for this finding. Nevertheless, it could be supposed that in the setting of complex coronary lesions, the most important determinants for major adverse cardiovascular events are related to lesions and procedural characteristic. Accordingly, positive prognostic factors in complex lesions described in previous registries are low bifurcation angle, use of drug eluting stents, performance of final kissing balloon and complete ostial coverage when using complex two-stents techniques [17,22-25]. In our population, although we miss data regarding bifurcation angle, we recorded similar lesions characteristics and procedural techniques despite age group. Moreover, final kissing balloon was performed with the same frequency in both groups. Thus, it could be postulated that once a complex lesion has developed, the age of the patients is not an independent prognostic factor. The angiographic complexity is such that by itself is enough to determine the outcome. Consequently, age per se was not strong enough to predict better outcomes in patients younger than 45 years. Moreover, since these data are drawn from an all-comers registry, it gives an important insight on outcomes of patients affected by complex coronary lesions in the real world practice.

Therefore, we can conclude that all patients treated with PCI of coronary bifurcation lesions face a non-irrelevant risk of early and late non-fatal adverse events. Younger patients do not fare differently from older patients, and they should not be denied aggressive risk factor modification, medical management and careful follow-up.

\subsection{Study limitations}

Our study had several limitations, including the non-randomized, observational design. This might have introduced confounding factors. Moreover, the two groups were not homogeneous for baseline characteristic and number, with older patients being over-represented when compared to younger patients. Also, young patients affected by ischemic heart disease may suffer from specific risk factors like coagulation anomalies and thrombophilia, which were not specifically investigated in our database. Finally, the selection of treatment strategies and stent types were at the discretion of the operators, thus having different attitude in younger and older patients, like the significantly different use of DES. Although we performed various risk-adjusted analyses, not all unmeasured variables and confounding factor might have been corrected. However, the observational design and the non-homogeneous populations represent the strength of this registry, that gives an idea of real world practice.

\subsection{Conclusion}

If it is true that increasing age is a negative prognostic factor, younger age does not necessarily mean risk reduction when dealing with percutaneous treatment of complex coronary lesions. Accordingly, the present study showed that despite their younger age, patients $<45$ years treated for coronary bifurcation lesions face a risk of adverse short-term and long-term outcome comparable with older patients. Thus, all patients deserve the same aggressive treatment on risk factor modification and close follow-up. Moreover, the finding that short and long-term risk of MACE is similar irrespective of age deserves further investigation.

\section{Acknowledgments}

All authors of this manuscript have certified that they comply with the Principles of Ethical Publishing in the International Journal of Cardiology" [36].

\section{References}

[1] Al Suwaidi J, Yeh W, Cohen HA, Detre KM, Williams DO, Holmes Jr DR. Immediate and one-year outcome in patients with coronary bifurcation lesions in the modern era (NHLBI dynamic registry). Am J Cardiol 2001;87:1139-44.

[2] Niemelä M, Kervinen K, Erglis A, et al. Randomized comparison of final kissing balloon dilatation versus no final kissing balloon dilatation in patients with coronary bifurcation lesions treated with main vessel stenting: the Nordic-Baltic Bifurcation Study III. Circulation 2011;123:79-86. 
[3] Chung SC, Hlatky MA, Faxon D, et al. The effect of age on clinical outcomes and health status BARI 2D (Bypass Angioplasty Revascularization Investigation in Type 2 Diabetes). J Am Coll Cardiol 2011;58:810-9.

[4] Alexander KP, Roe MT, Chen AY, et al. Evolution in cardiovascular care for elderly patients with non-ST-segment elevation acute coronary syndromes: results from the CRUSADE National Quality Improvement Initiative. J Am Coll Cardiol 2005;46: 1479-87.

[5] Cohen HA, Williams DO, Holmes Jr DR, et al. Impact of age on procedural and 1-year outcome in percutaneous transluminal coronary angioplasty: a report from the NHLBI Dynamic Registry. Am Heart J 2003;146:513-9.

[6] Granger CB, Goldberg RJ, Dabbous O, et al. Predictors of hospital mortality in the global registry of acute coronary events. Arch Intern Med 2003;163:2345-53.

[7] Rosengren A, Wallentin L, Simoons M, et al. Age, clinical presentation, and outcome of acute coronary syndromes in the Euroheart acute coronary syndrome survey. Eur Heart J 2006;27:789-95.

[8] Romagnoli E, De Servi S, Tamburino C, et al. Real-world outcome of coronary bifurcation lesions in the drug-eluting stent era: results from the 4,314-patient Italian Society of Invasive Cardiology (SICI-GISE) Italian Multicenter Registry on Bifurcations (I-BIGIS). Am Heart J 2010;160:535-542 e1.

[9] Biondi-Zoccai G, Sheiban I, Romagnoli E, et al. Is intravascular ultrasound beneficial for percutaneous coronary intervention of bifurcation lesions? Evidence from a 4,314-patient registry. Clin Res Cardiol 2011;100:1021-8.

[10] Colombo A, Bramucci E, Saccà S, et al. Randomized study of the crush technique versus provisional side-branch stenting in true coronary bifurcations: the CACTUS (Coronary Bifurcations: Application of the Crushing Technique Using Sirolimus-Eluting Stents). Study Circ 2009;119:71-8.

[11] Medina A, Suarez de Lezo J, Pan M. [A new classification of coronary bifurcation lesions]. Rev Esp Cardiol 2006;59:183.

[12] Thygesen K, Alpert JS, White HD. Universal definition of myocardial infarction. J Am Coll Cardiol 2007;50:2173-95.

[13] Cutlip DE, Windecker S, Mehran R, et al. Clinical end points in coronary stent trials: a case for standardized definitions. Circulation 2007;115:2344-51.

[14] Colombo A, Chieffo A. Drug-eluting stent update 2007: part III: Technique and unapproved/unsettled indications (left main, bifurcations, chronic total occlusions, small vessels and long lesions, saphenous vein grafts, acute myocardial infarctions, and multivessel disease). Circulation 2007;116:1424-32.

[15] Tanabe K, Hoye A, Lemos PA, Aoki J, et al. Restenosis rates following bifurcation stenting with sirolimus-eluting stents for de novo narrowings. Am J Cardiol 2004;94:115-8.

[16] Al Suwaidi J, Berger PB, Rihal CS, et al. Immediate and long-term outcome of intracoronary stent implantation for true bifurcation lesions. J Am Coll Cardiol 2000;35:929-36.

[17] Iakovou I, Ge L, Colombo A. Contemporary stent treatment of coronary bifurcations. J Am Coll Cardiol 2005;46:1446-55.

[18] Song YB, Hahn JY, Choi SH, et al. Sirolimus- versus paclitaxel-eluting stents for the treatment of coronary bifurcations results: from the COBIS (Coronary Bifurcation Stenting) Registry. J Am Coll Cardiol 2010;55:1743-50.

[19] Ferenc M, Gick M, Kienzle RP, et al. Randomized trial on routine vs. provisional T-stenting in the treatment of de novo coronary bifurcation lesions. Eur Heart 2008;29:2859-67.
[20] Feldman DN, Gade CL, Slotwiner AJ, et al. Comparison of outcomes of percutaneous coronary interventions in patients of three age groups $(<60,60$ to 80 , and $>80$ years) (from the New York State Angioplasty Registry). Am J Cardiol 2006;98:1334-9.

[21] Wilson WM, Andrianopoulos N, Clark D, et al. Long-term predictors of mortality after percutaneous coronary intervention in the era of drug-eluting stents. Am J Cardiol 2011;108:936-42.

[22] Brandes RP, Fleming I, Busse R. Endothelial aging. Cardiovasc Res 2005;66:286-94.

[23] Robert L. Aging of the vascular-wall and atherosclerosis. Exp Gerontol 1999;34: 491-501.

[24] Moussa I, Costa RA, Leon MB, et al. A prospective registry to evaluate sirolimuseluting stents implanted at coronary bifurcation lesions using the "crush technique". Am J Cardiol 2006;97:1317-21.

[25] Lefèvre T, Ormiston J, Guagliumi G, et al. The Frontier stent registry: safety and feasibility of a novel dedicated stent for the treatment of bifurcation coronary artery lesions. J Am Coll Cardiol 2005;46:592-8.

[26] Yamashita T, Nishida T, Adamian MG, et al. Bifurcation lesions: two stents versus one stent-immediate and follow-up results. J Am Coll Cardiol 2000;35:1145-51.

[27] Lefèvre T, Louvard Y, Morice MC, et al. Stenting of bifurcation lesions: classification, treatments, and results. Catheter Cardiovasc Interv 2000;49:274-83.

[28] Ge L, Airoldi F, Iakovou I, et al. Clinical and angiographic outcome after implantation of drug-eluting stents in bifurcation lesions with the crush stent technique: importance of final kissing balloon post-dilation. J Am Coll Cardiol 2005;46: 613-20.

[29] Routledge HC, Morice MC, Lefèvre T, et al. 2-year outcome of patients treated for bifurcation coronary disease with provisional side branch T-stenting using drug-eluting stents. JACC Cardiovasc Interv 2008;1:358-65.

[30] Zimmerman FH, Cameron A, Fisher LD, Ng G. Myocardial infarction in young adults: angiographic characterization, risk factors and prognosis (Coronary Artery Surgery Study Registry). J Am Coll Cardiol 1995;26:654-61.

[31] Hosseini SK, Soleimani A, Karimi AA, et al. Clinical features, management and in-hospital outcome of ST elevation myocardial infarction (STEMI) in young adults under 40 years of age. Monaldi Arch Chest Dis 2009;72:71-6.

[32] Badran HM, Elnoamany MF, Khalil TS, Eldin MM. Age-related alteration of risk profile, inflammatory response, and angiographic findings in patients with acute coronary syndrome. Clin Med Cardiol 2009;3:15-28.

[33] Chua SK, Hung HF, Shyu KG, et al. Acute ST-elevation myocardial infarction in young patients: 15 years of experience in a single center. Clin Cardiol 2010;33:140-8.

[34] Tang EW, Wong CK, Herbison P. Global Registry of Acute Coronary Events (GRACE) hospital discharge risk score accurately predicts long-term mortality post acute coronary syndrome. Am Heart J 2007; 153:29-35.

[35] Malmberg K, Yusuf S, Gerstein HC, et al. Impact of diabetes on long-term prognosis in patients with unstable angina and non-Q-wave myocardial infarction: results of the OASIS (Organization to Assess Strategies for Ischemic Syndromes) Registry. Circulation 2000;102:1014-9.

[36] Coats AJS, Shewan LG. Statement on Authorship and Publishing Ethics in the International Journal of Cardiology. Int J Cardiol 2011;153:239-40. 